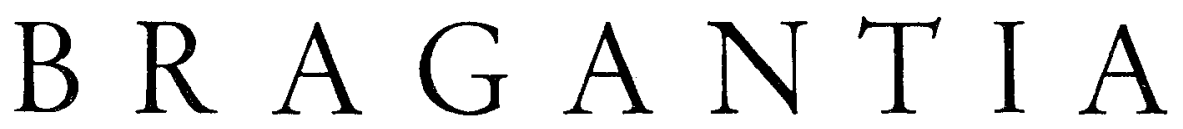

Boletim Científico do Instituto Agronómico do Estado de São Paulo

Vol. 25

Campinas, junho de 1966

N. 5

\title{
APLICAÇÃO DE NITROGÊNIO EM COBERTURA, EM CULTURA DE ARROZ $\left({ }^{1}\right)$
}

Nelson C. SCHMid, engenheiro-agrônomo, Estaçăo Experimental de Pindamonhangaba, e Hermano Gargantini, engenheiro-agrônomo, Seção de Fertilidade do Solo, Instituto Agronômico

\section{SINOPSE}

Com o objetivo de estudar a aplicação do sulfato de amônio em cobertura, em cultura de arroz (oryza sativa L.), foi conduzido o presente experimento, em solo argiloso de várzea, da Estação Experimental de Pindamonhangaba, no Vale do Paraiba. Estudou-se, ainda, o efeito de doses crescentes de nitrogênio e de fósforo.

Estudaram-se cinco niveis de nitrogênio, três de fósforo e sòmente um de potássio. A variedade foi a Iguape-agulha, e a cultura foi irrigada por inundação, como de hábito na região.

Os resultados obtidos indicam grande eficiência da aplicação do sulfato de amônio em cobertura, quando efetuada entre os 30 e 50 dias após a germinação. As respostas encontradas para níveis de nitrogênio foram lineares e significativas, indicando que, nas condiçôes do ensaio, mesmo a aplicação de $120 \mathrm{~kg} / \mathrm{ha}$ do elemento ainda foi eficiente no aumento da produção. Não foi observada reação alguma à adubação fosfatada.

\section{1 - INTRODUÇÃO}

A aplicação de fertilizantes nitrogenados em cobertura, na cultura do arroz, seja irrigada ou em condições de sequeiro, ainda é uma prática muito pouco utilizada no Estado de São Paulo.

Não são muitos os trabalhos experimentais conhecidos que mostram efeito benéfico à produção do arroz, da aplicação de nitrogênio em cobertura. Isto, principalmente para o tipo de cultura mais usual em São Paulo nas condições de várzea irrigada, que é o plantio direto da semente (plantio mecânico). Já para a cultura do arroz por transplante ou plantio pré-germinado, onde se irriga desde o plantio até a colheita, a literatura sôbre experimentos de adubação é vasta.

(1) Recebido para publicação em 18 de novembro de 1965. 
Galvez (3), em ensaios conduzidos nas Filipinas, mostrou que $1 / 3$ do nitrogênio deve ser aplicado por ocasião do plantio, e os $2 / 3$ restantes, em cobertura, vinte dias antes do florescimento. Essa forma de adubação prevê para a cultura suprimento suficiente do elemento durante todo o desenvolvimento vegetativo e de granação. Em solo suficientemente suprido de nitrogênio, basta a aplicação suplementar em cobertura.

Schmidt e Gargantini (6), trabalhando em solos argilosos de várzea, em cultura irrigada por inundação, combinada com drenagem, mostraram que o nitrogênio, na base de $40 \mathrm{~kg} / \mathrm{ha}$ e aplicados $20 \%$ por ocasião da semeadura e o restante em cobertura, trouxe os maiores aumentos de produção de grãos.

Bernardes e Mohr (1) apresentam ensaio conduzido na Estação Experimental de Arroz, em Gravataí, RS, onde melhores resultados foram os obtidos com a aplicação de sulfato de amônio, 6 a 10 semanas após o plantio.

Wells (8) estudou o efeito da época de aplicação de fertilizantes nitrogenados, em ensaios conduzidos durante dois anos, com duas variedades. As duas variedades se comportaram diferentemente. Uma delas apresentou melhores respostas quando o nitrogênio foi colocado entre 65 a 75 dias após o plantio, enquanto que na outra se destacou a aplicação feita entre 75 e 85 dias após o plantio.

Geus (4) reporta-se a uma série de experimentos com arroz de muda, mostrando que a aplicação em cobertura de fertilizantes nitrogenados não apresentou melhores resultados que a aplicação dêsse nutriente em profundidade.

Davis e Jones (2) apresentam ensaios conduzidos durante quatro anos, nos quais estudaram a aplicação de $150 \mathrm{~kg} / \mathrm{ha}$ de sulfato de amônio em três épocas distintas: por ocasião do plantio, aos 55 dias e aos 100 dias após o plantio. Concluem que o melhor efeito dêsse fertilizante, na média dos quatro anos, foi obtido com a aplicação por ocasião do plantio.

Peterson (5) relata experimento em que foram iguais as respostas ao nitrogênio aplicado em cobertura ou por ocasião do plantio.

Com o objetivo de estudar o efeito da adubação em cobertura com sulfato de amônio, em cultura de arroz irrigado, bem como diversas dosagens de nitrogênio e de fósforo, é que foi conduzido o experimento relatado no presente trabalho.

\section{2 - MATERIAIS E MÉTODOS}

O ensaio foi instalado na Estação Experimental de Pindamonhangaba, no município do mesmo nome, situado no Vale do Paraíba, Estado de São Paulo. O solo utilizado foi classificado e mapeado por Verdade e outros (7) como série Dourada. 
Do local do experimento foi retirada uma amostra composta, que apresentou as seguintes características químicas:

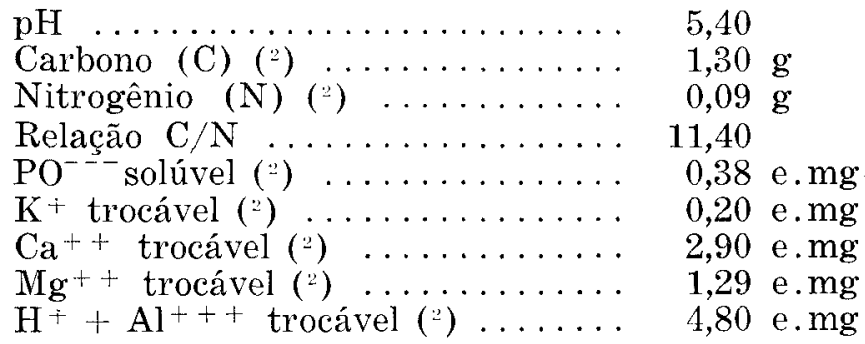

O delineamento experimental utilizado foi o de blocos ao acaso com três repetições, constando dos treze tratamentos seguintes:

1 - 000 - Testemunha (sem adubo)

$2-0 \mathrm{P}_{1} \mathrm{~K}-\operatorname{sem} \mathrm{N}$

3 - $N_{1} P_{1} K$ - Todo o $N$ no sulco, por ocasião do plantio

4 - $\mathrm{N}_{1} \mathrm{P}_{1} \mathrm{~K}-\mathrm{N}$ em cobertura aos 30 dias (")

$5-\mathrm{N}_{1} \mathrm{P}_{1} \mathrm{~K}-\mathrm{N}$ em cobertura aos 40 dias

6 - $\mathrm{N}_{1} \mathrm{P}_{1} \mathrm{~K}-\mathrm{N}$ em cobertura aos 50 dias

7 - $\mathrm{N}_{2} \mathrm{P}_{1} \mathrm{~K}$ - $\mathrm{N}$ em cobertura aos 40 dias

$8-\mathrm{N}_{3} \mathrm{P}_{1} \mathrm{~K}-\mathrm{N}$ em cobertura aos 40 dias

$9-\mathrm{N}_{4} \mathrm{P}_{1} \mathrm{~K}-\mathrm{N}$ em cobertura aos 40 dias

$10-\mathrm{N}_{5} \mathrm{P}_{1} \mathrm{~K}$ - $\mathrm{N}$ em cobertura aos 40 dias

$11-\mathrm{N}_{1} \mathrm{P}_{2} \mathrm{~K}-\mathrm{N}$ em cobertura aos 40 dias

12 - $\mathrm{N}_{1} \mathrm{P}_{3} \mathrm{~K}-\mathrm{N}$ em cobertura aos 40 dias

$13-\mathrm{N}_{1} \mathrm{P}_{0} \mathrm{~K}-\mathrm{N}$ em cobertura aos 40 dias

Com êsses tratamentos foram estudados cinco níveis de nitrogênio, três de anidrido fosfórico e sòmente um de potássio. Os fertilizantes empregados foram sulfato de amônio, superfosfato simples e cloreto de potássio.

Os níveis utilizados de nitrogênio foram $0,40,60,80,100$ e 120 $\mathrm{kg} / \mathrm{ha}$, aplicados em todos os tratamentos na base de $20 \%$ da dose por ocasião do plantio das sementes, juntamente com a dosagem total de fósforo e potássio. A parte restante da dose de nitrogênio foi colocada em cobertura, ao lado das linhas de arroz. Os níveis de fósforo foram $0,80,120$ e $160 \mathrm{~kg} /$ ha; de potássio, utilizou-se sempre o nível de $40 \mathrm{~kg} / \mathrm{ha}$.

A variedade de arroz foi a Iguape-agulha, utilizando-se o método do plantio direto, com a densidade de duas gramas de semente por metro de sulco. 
As parcelas tiveram uma área total de $12 \mathrm{~m}^{2}$, constando de cinco linhas espaçadas de $40 \mathrm{~cm}$, por $6 \mathrm{~m}$ de comprimento. Para fins do ensaio, colheram-se sòmente as três linhas centrais, resultando uma área útil de $7,2 \mathrm{~m}^{2}$.

O plantio do arroz foi feito em dezembro de 1962, tendo germinado seis dias após. O "stand" inicial, ótimo, manteve-se excelente até o final do ensaio. Não foi observado ataque de pragas e de moléstias durante todo o transcorrer do ensaio.

O sistema de irrigação e drenagem, individual e igual para todos os tratamentos, permitiu a obtenção de resultados bastante uniformes. A técnica seguida, bem como a forma de irrigação utilizada, foi a mesma já descrita por Schmidt e Gargantini (6). A irrigação e a drenagem foram independentes, permitindo retirar ou colocar água em cada canteiro, de acôrdo com o tratamento. O sistema de irrigacão empregado, do tipo de inundação, consiste em irrigar a cultura 10 dias após a germinação, retirar a água aos 30 dias, irrigar novamente, sòmente retirando a água nas proximidades da colheita. A altura da água mantida nos canteiros foi de $10 \mathrm{~cm}$ nos primeiros 30 a 40 dias, elevando-se depois para $20 \mathrm{~cm}$, conforme o desenvolvimento das plantas.

As coberturas com sulfato de amônio foram efetuadas aos 30 , 40 e 50 dias após a germinação. Nos tratamentos onde se compararam os niveis de nitrogênio, manteve-se fixa a data de aplicação dêsse nutriente, ou seja, aos 40 dias após a germinação. Na época de aplicação do nitrogênio em cobertura, drenavam-se os canteiros, distribuia-se o sulfato de amônio sôbre o solo, ao lado das linhas de plantas, e sòmente dois dias após reiniciava-se a irrigação.

Em abril de 1963 procedeu-se à colheita do arroz. Após a colheita, o arroz foi batido, pesando-se separadamente a palha e os grãos. Êstes, depois de secos, foram abanados, dando finalmente o pêso obtido em cada tratamento.

\section{3 - RESULTADOS E DISCUSSÃO}

Os dados da produção de palha e de grãos constam do quadro 1.

Os resultados obtidos mostram grande reação da cultura aos nutrientes aplicados. Tomando-se inicialmente os dados da produção de palha, verifica-se ter havido grande aumento quando os tratamentos receberam adubação. As diferenças encontradas foram altamente significativas. Nos tratamentos onde entrou a adubação nitrogenada, as produções foram muito superiores às dos canteiros que não receberam essa adubação.

Verifica-se que o pêso da palha cresceu com o aumento das doses de nitrogênio. A análise da variância mostrou haver reação linear e altamente significativa. Não foi encontrada reação aos níveis de fósforo. 
QUADro 1. - Produçōes de palha (colmos + fôlhas) e grāos com casca por canteiro de $7,2 \mathrm{~m}^{2}$, obtidas em experimento de adubação de arroz cultivado com irrigação na Estação Experimental de Pindamonhangaba, em 1962/63

\begin{tabular}{|c|c|c|}
\hline \multirow{2}{*}{ Tratamentos } & \multicolumn{2}{|c|}{ Produçōes } \\
\hline & Palha & Grãos \\
\hline & $k g$ & $k g$ \\
\hline $1-000-$ Testemunha & 3,20 & 0,93 \\
\hline $2-0 P_{r} K-\operatorname{sem} N \ldots \ldots \ldots$ & 4,77 & 1,00 \\
\hline $3-\mathrm{N}_{1} \mathbf{P}_{1} \mathbf{K}-\mathrm{N}$ no sulco $\ldots \ldots \ldots$ & 5,00 & 1,30 \\
\hline $4-\mathrm{N}_{1} \mathbf{P}_{1} \mathbf{K}-$ Cobertura 30 dias $* \ldots$ & 6,67 & 1,76 \\
\hline $5-\mathrm{N}_{2} \mathbf{P}_{2} \mathbf{K}$ - Cobertura 40 dias $* \ldots$ & 5,59 & 1,48 \\
\hline $6-\mathrm{N}_{\mathrm{y}} \mathrm{P}_{\mathrm{I}} \mathrm{K}$ - Cobertura 50 dias ${ }^{*} \ldots$ & 5,17 & 1,56 \\
\hline $7-\mathrm{N}_{2} \mathbf{P}_{1} \mathrm{~K}-$ Cobertura 40 dias $* \ldots$ & 5,45 & 1,85 \\
\hline $8-\mathrm{N}_{3} \mathrm{P}_{1} \mathrm{~K}-$ Cobertura 40 dias * $\ldots$ & 8,15 & 2,05 \\
\hline $9-\mathbf{N}_{4} \mathbf{P}_{x} \mathbf{K}-$ Cobertura 40 dias $* \ldots$ & 8,99 & 2,01 \\
\hline $10-\mathrm{N}_{\mathrm{s}} \mathrm{P}_{\mathrm{t}} \mathrm{K}-$ Cobertura 40 dias $* \ldots$ & $1 \mathrm{C}, 87$ & 2,26 \\
\hline 11 - $\mathrm{N}_{1} \mathrm{P}_{2} \mathrm{~K}$ - Cobertura 40 dias $* \ldots$ & 5,67 & 1,56 \\
\hline $12-\mathbf{N}_{1} \mathbf{P}_{3} \mathrm{~K}-$ Cobertura 40 dias $* \ldots$ & 5,97 & 1,66 \\
\hline 13 - $\mathrm{N}_{1} \mathrm{P}_{0} \mathrm{~K}$ - Cobertura 40 dias * ... & 6,34 & 1,60 \\
\hline
\end{tabular}

* $20 \%$ do N no sulco, por ocasiāo do plantio, e $80 \%$ em cobertura.

Passando-se à produção de grãos, novamente verifica-se muito grande reação da cultura à aplicação dos fertilizantes. Encontrou-se, na análise da variância, diferença altamente significativa entre os tratamentos adubados e o que não recebeu adubação.

A aplicação de fósforo não mostrou reação alguma da cultura. Comparando-se os tratamentos que receberam adubação fosfatada, com o tratamento 13 , sem fósforo, verifica-se claramente não ter havido resposta à êsse elemento fertilizante, nem mesmo quando se elevou a sua dosagem. Pode-se explicar a falta de reação ao fósforo pela análise do solo, que apresentou teor bastante alto do elemento.

Ao nitrogênio, no entanto, a reação encontrada foi muito grande, como pode ser verificada. A comparação entre as épocas de aplicação, 30,40 e 50 dias após a germinação, não apresentou diferença de produção.

As reações às aplicações em cobertura de sulfato de amônio foram muito grandes, ocorrendo aumentos de produções proporcionais aos níveis do elemento aplicados. O tratamento 10, que recebeu $120 \mathrm{~kg} / \mathrm{ha}$ de $\mathrm{N}$, apresentou a maior produção de grãos. A análise da variância mostrou serem os aumentos, devidos ao nitrogênio, lineares e altamente significativos. O coeficiente de variação, $14,8 \%$, indica boa precisão do ensaio. 


\section{4 - CONCLUSõES}

Do ensaio relatado, as seguintes conclusões podem ser tiradas:

a) a adubação com sulfato de amônio em cobertura foi altamente eficiente para a produção de grãos do arroz cultivado em várzea irrigada.

b) o efeito do nitrogênio foi altamente significativo e linear, mostrando a necessidade de outros ensaios com dosagens maiores de sulfato de amônio.

c) o fertilizante fosfatado não apresentou reação alguma.

d) não houve diferenças de produção entre aplicações em cobertura de nitrogênio feitas 30, 40 ou 50 dias após a germinação.

\section{APPLICATION OF NITROGEN AS TOP DRESSING \\ IN RICE CROPS}

\section{SUMMARY}

This paper reports about an experiment carried out in argillaceous soil of lowlands, located at the Experiment Station of Pindamonhangaba, in the Paraiba River valley, and had in view the study of application of ammonium sulfate as top dressing, in rice crops. This same trial had further the purpose to find out which were the necessary doses of nitrogen that led to major production as 'well as the levels of phosphorus required for a good development and good yield of rice.

The experimental lay-out used was that of ransom blocks where 5 doses of nitrogen were applied, 3 of phosphorus and one only of potassium. The variety of rice (Oryza sativa) used was the Iguape Agulha the culture being submitted to flood irrigation, which is the type common to the rice crops in that region of the State.

The results obtained indicate the great efficiency toward increase of yield by application as top dressing of the ammonium sulfate. This fertilizer should be applied in the period between 30 and 50 days after germination. Responses determined by the doses of nitrogen were linear and significant, indicating that under the conditions of the trial, even the application of $120 \mathrm{~kg}$ per hectare of the element was still efficient for the increase of production. As for the phosphorous fertilizer no reaction whatever was observed.

\section{LITERATURA CITADA}

1. Bernardes, B. C. \& Mohr, W. Cultura e adubaçāo do arroz. Rio Grande do Sul, novembro 1962. (Boletim)

2. Davis, L. L. \& Jones, J. W. Fertilizer Experiments With Rice in California. Washington, United States Department of Agriculture, 1940. 21p. (Technical Bulletin . $^{\circ} 718$ ) 
3. Galvez, N. L. Some factors affecting fertilization of paddy soils. Transactions of 7th International Congress of Soil Science. Madison, 1960. 268-275.

4. Geus, J. G. de. Means of increasing rice production. Geneva, Centre d'Étude de l'Azote, 1954. 143p.

5. Peterson, F. J. Time of Application of Fertilizer. In Louisiana, Rice Experiment Station, 1962, 86-88 (54th Annual Progress Report)

6. Schmidt, N. C. \& Gargantini, H. Adubação nitrogenada para arroz em solos argilosos de várzea. Bragantia 22:[367]-372. 1963.

7. Verdade, F. C., Hungria, L. S., Russo, R. [e outro]. Solos da Bacia de Taubaté (Vale do Paraiba), Levantamento de reconhecimento, séries monotípicas, suas propriedades genético-morfológicas, físicas e quimicas. Bragantia $20:[43]-322.1961$.

8. Wells, J. P. Effect of Timing of Nitrogen Fertilization on Rice Yields. Arkansas, Agricultural Experiment Station, 1962. 17p. (Report Series 112) 